\title{
Abses Submandibula dengan Komplikasi Mediastinitis
}

\author{
Agus Santosa ${ }^{1,2}$ \\ ${ }^{\text {I} B a g i a n ~ K S M ~ T H T ~ B r o s ~ H o s p i t a l, ~}$ \\ ${ }^{2}$ Fakultas Kedokteran dan Ilmu Kesehatan Universitas Warmadewa, Denpasar \\ Email: omangbabe@gmail.com
}

\begin{abstract}
Abstrak
Abses leher dalam terbentuk di dalam ruang potensial di antara fasia leher sebagai akibat perjalanan infeksi dari berbagai sumber seperti gigi, mulut, tenggorok, sinus paranasal, telinga tengah dan leher. Tergantung ruang mana yang terlibat, gejala dan tanda klinik setempat berupa nyeri dan pembengkakan akan menunjukkan lokasi infeksi. Ruang submandibular adalah lokasi yang paling sering ditemui pada infeksi ruang leher dalam. Paling sering terjadi pada usia 20 dan 60 tahun, dengan dominasi laki-laki dibandingkan perempuan adalah 3:1. Penyebab abses ini yang paling sering adalah infeksi gigi. Penyebaran infeksi sepanjang danger space cepat dapat menyebabkan mediastinitis. Dilaporkan satu kasus abses submandibular penderita, laki-laki 41 tahun datang dengan keluhan bengkak pada pipi dan rahang bawah kanan disertai demam sejak kurang lebih 8 hari sebelum MRS. Sebelumnya penderita mengeluh sakit pada gigi geraham kanan bawah. Penderita juga mengeluh batuk dan sesak sejak 2 hari sebelum MRS. Pada aspirasi didapatkan pus kemudian insisi dan drainase. Pasien dilakukan pemeriksaan penunjang dan didapatkan hasil suspek mediastinitis. Pasien dikonsulkan kepada BedahThorak-Kardiovaskuler dan dilakukan sternotomy. Pasien mengalami perbaikan kondisi dan pasien diijinkan untuk pulang kerumah.
\end{abstract}

Kata Kunci: laki-laki, infeksi gigi, abses, mediastinitis

\section{Abstract}

[Submandibular Abscess With Complications Mediastinitis]

Abscesses in the neck formed in the potential space between the fascia of the neck as a result of the course of infection from various sources such as the teeth, mouth, throat, paranasal sinuses, middle ear and neck. Depending on the space involved, the symptoms and signs of local pain and swelling will the location of the infection. Submandibular space is the location of the most commonly encountered in infections in the neck area. Most often between the ages of 20 and 60 years, with a predominance of males compared to females was 3:1. The cause of this abscess is most commonly a dental infection. The spread of infection throughout the danger space can immediately lead to mediastinitis. Reported a case of submandibular abscess patient, 41 years old male presents with swelling on the right cheek and lower jaw, with fever since at least 8 days prior. Previous patient complained of pain in the lower right molar teeth. Patients also complained of cough and shortness since two days. Then aspiration obtained pussy then incision and draignase. Patients be investigated and the results obtained suspected mediastinitis. Patients consulted for Thoracic Surgery-Cardiovascular and do sternotomy. Patients experiencing improved conditions and the patient is allowed to go home.

Keywords: male, tooth infection, abscess, mediastinitis

\section{LATAR BELAKANG}

Abses leher dalam terbentuk dalam ruang potensial di antara fasia leher sebagai akibat perjalanan infeksi dari berbagai sumber seperti gigi, mulut, tenggorok, sinus paranasal, telinga tengah dan leher. Yang termasuk abses leher dalam ialah abses peritonsil, abses parafaring, abses retrofaring dan angina ludovici (angina Ludwig) atau abses submandibula. ${ }^{[1]}$ Ruang submandibu- lar adalah lokasi yang paling sering ditemui pada infeksi ruang leher dalam. ${ }^{[2]}$

Infeksi leher dalam biasa ditemui pada anak maupun orang dewasa. Namun presentasi, progresifitas dan penatalaksanaan-nya sangat berbeda dalam dua kelompok usia tersebut. ${ }^{[3,4]}$ Keterlambatan dalam diagnosis, atau lebih buruk lagi, kesalahan diagnosis, dapat mengakibatkan terjadinya mediastinitis dan kematian. Bahkan 
di era antibiotik modern, telah dilaporkan angka kematian mencapai $40 \%{ }^{[5]}$

Obstruksi jalan napas dan penyebaran infeksi ke mediastinum adalah komplikasi yang paling sulit penanganannya dari infeksi ruang submandibula. Insisi dan drainase secara dini harus selalu dipertimbangkan pada pasien, bahkan dalam kasus-kasus yang tampaknya tidak kritis. ${ }^{[6]}$

Abses leher dalam masih dihubungkan dengan angka kesakitan dan angka kematian yang tinggi bila disertai komplikasi. Meskipun ada peningkatan dalam hal perawatan gigi dan hygiene rongga mulut, tapi baru-baru ini dikemukakan prevalensi yang bermakna dari infeksi leher dalam yang disebabkan oleh infeksi gigi lebih dari $40 \%$. ${ }^{[7]}$

\section{LAPORAN KASUS}

Penderita, AAM, laki-laki 41 tahun pada tanggal 22 Mei 2016 datang ke UGD RS Bros dengan keluhan bengkak pada pipi dan rahang bawah kanan sejak kurang lebih 8 hari. Sebelumnya penderita mengeluh sakit pada gigi geraham kanan bawah. Penderita juga mengeluh panas sejak 5 hari dan agak sulit membuka mulut sehari sebelum MRS. Penderita hanya bisa makan dan minum sedikit-sedikit. Penderita juga mengeluh batuk dan sesak 2 hari sebelum MRS. Menurut keluarga penderita ada riwayat gigi geraham kiri bawah berlubang dan memiliki riwayat penyakit kusta tidak terkontrol. Pasien minum obat kortikostreoid tanpa resep dari dokter. Dari pemeriksaan fisik umum ditemukan: penderita dengan keadaan umum lemah, tensi $100 / 70 \mathrm{mmHg}$, nadi 90 kali permenit, respirasi $26 \mathrm{kali}$ permenit dan temperatur aksila $38^{0} \mathrm{C}$. Pada pemeriksaan status lokalis THT didapatkan, pada pemeriksaan telinga KAE: lapang/ lapang, MT: intak/ intak, reflek cahaya $+/+$, sekret: -/-. Pada pemeriksaan hidung, KN: lapang/lapang, mukosa: merah muda/merah muda, sekret: -/-. Pemeriksaan tenggorok tidak dapat dilakukan karena penderita mengalami trismus kurang lebih $1,5 \mathrm{~cm}$. Pemeriksaan leher tampak kemerahan, bengkak tanpa fluktuasi. Tampak pem- bengkakan pada daerah submandibula kanan dengan ukuran $5 \mathrm{~cm}$ x $4 \mathrm{~cm} \times 2 \mathrm{~cm}$ disertai hiperemi, nyeri tekan dan tampak adanya fluktuasi. Kemudian dilakukan aspirasi dengan hasil pus + dan dilakukan pemeriksaan kultur. Dari hasil pemeriksaan laboratorium pada penderita, pemeriksaan darah lengkap diperoleh hasil WBC 22,91 x $10^{3} / \mu \mathrm{L}$.

Berdasarkan anamnesa dan pemeriksaan fisik tersebut serta didukung hasil pemeriksaan laboratorium, penderita didiagnosis: abses submandibula sinistra susp mediastinitis. Penderita dikonsulkan sejawat Bedah Trauma Kardiovaskuler, sejawat kulit dan kelamin, sejawat gigi dan mulut serta sejawat penyakit dalam. Jawaban dari sejawat gigi dan mulut oenderita direncanakan panoramic bila kondisi sudah stabil. Jawaban sejawat kulit kelamin rencana dilakukan terapi $\mathrm{MH}$ bila kondisi pasien stabil karena terapinya memerlukan waktu yang panjang. Jawaban dari sejawat penyakit dalam penderita didapatkan dengan Diabetes mellitus dan diberikan inj novorapid serta dilakukan pemeriksaan gula darah tiap hari sampai stabil. Jawaban sejawat BTKV saran dilakukan CT-Scan dan draignase serta sternotomy. Penderita dilakukan tindakan insisi-drainase untuk mengeluarkan pus. Penderita cukup kooperatif sehingga tindakan ini bisa dilakukan dengan pemberian anestesi lokal. Insisi dilakukan dengan panjang kurang lebih $2 \mathrm{~cm}$ pada daerah yang paling fluktuatif. Setelah insisi, eksplorasi pus dilanjutkan secara tumpul dengan menggunakan klem bengkok sampai ruang submandibula. Setelah pus berhasil dieksplorasi, dilakukan pemasangan drain handschoen pada luka insisi dan ditutup dengan kasa yang dibasahi dengan $\mathrm{NaCl} 0,9 \%$ yang dicampur dengan larutan antiseptik. Penderita dievaluasi setiap hari dan dilakukan dilatasi pada luka insisi untuk mengeluarkan pus yang masih diproduksi.

Hasil CT-Scan abscess formation yang luas dari retromandibular kiri ( region parotis gland), ke submandibular kiri, sucutis colli kanan-kiri-anterior, di retrosternoclavicula joint kanan kiri, melebar ke sisi 
kanan di supraclavicular kanan, bahu kanan anterior os scapula kanan sampai setinggi costae 5 kanan-posterior. Sebagai terapi parenteral penderita diberikan IVFD $\mathrm{NaCl}$ $0,9 \% 1500 \mathrm{ml}$ per hari, sesuai dengan 20 tetes/menit. Ceftriaxon $2 \times 1000 \mathrm{mg} \mathrm{IV}$, Metronidazole drip 3 x $500 \mathrm{mg}$ IV, Nutriflam $2 \times 1$ caps, dan vectrin sirup 3x C1 dan penderita dirawat dengan posisi Trendelenberg. Pada tanggal 23 Mei 2016 dilakukan incise draignase dan sternotomy dengan temuan pus dileher dan rahang bawah sebanyak kurang lebih 300 cc dan dilakukan sternotomy. Selama dirawat, keadaan penderita terus membaik. Trismus berkurang, pus dari luka insisi sudah tidak ada dan luka insisi mulai menutup. Hasil kultur menunjukkan hasil mikroorganisme Klebsiella oxytoca yang sensitif terhadap amoksisilin-asam klavulanat, cefotaxime, doxycycline, cefoperazone, ceftriaxone, levofloxacin, dan meropenem. Pada tanggal 31 Mei 2016 penderita dipulangkan dengan obat cefixime $2 \times 100 \mathrm{mg}$ tab intraoral. Penderita disarankan untuk kontrol kembali

\section{PEMBAHASAN}

Abses Submandibula adalah penyakit yang dapat berpotensi mengancam nyawa jika proses infeksinya menyebar sampai ke mediastinum. Kondisi predisposisi adalah diabetes mellitus, neutropenia, alkoholisme, anemia aplastik, glomerulonephritis, dermatomiositis, dan lupus eritematous sistemik. ${ }^{[2]}$ Paling sering terjadi pada usia 20 dan 60 tahun, dengan dominasi perbandingan laki-laki dan perempuan 3 : 1 . Angka kematian akibat abses submandibula sebelum dikenalnya antibiotika mencapai 50\% dari seluruh kasus yang dilaporkan, sejalan dengan perkembangan antibiotika, perawatan bedah yang baik dan tindakan yang cepat dan tepat, maka saat ini angka kematian hanya $5 \% .^{[3-5]}$

Penyebab abses ini yang paling sering adalah infeksi gigi. Nekrosis pulpa karena karies dalam yang tidak terawat dan periodontal pocket dalam merupakan jalan bakteri untuk mencapai jaringan periapikal. [6] Odontogen dapat menyebar melalui jaringan ikat, pembuluh darah, dan pem- buluh limfe. Yang paling sering terjadi adalah perkontinuitatum karena adanya celah atau ruang diantara jaringan yang berpotensi sebagai tempat berkumpulnya pus. ${ }^{[8-9]}$

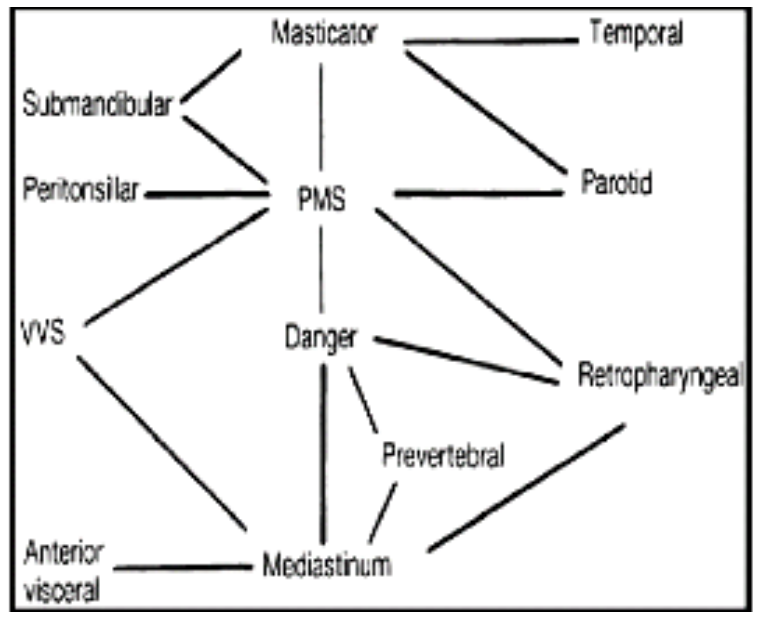

Gambar 1 Pola penyebaran infeksi pada ruang potensial leher dalam $P M S$ = pharyngomaxilary space/ruang parafaring, $V V S=$ visceral vascular space $^{[10]}$

Perjalanan infeksi pada rahang atas dapat membentuk abses palatal, abses submukosa, abses gingiva, thrombosis sinus kavernosus, abses labial, dan abses fasial. Perjalanan infeksi pada rahang bawah dapat membentuk abses sublingual, submental, abses submandibular, abses submaseter, dan angina Ludovici. Ujung akar molar kedua dan ketiga terletak di belakang bawah linea milohioid yang terletak di aspek dalam mandibular, sehingga jika molar kedua atau ketiga terinfeksi dan membentuk abses, pus akan menyebar ke ruang submandibular dan dapat meluas ke ruang potensial leher yang paling sering menyebar ke mediastinum. ${ }^{[3,5,6]}$

Organisme penyebab yang lazim ditemukan seperti Streptococcus viridans, Staphylococcus epidermidis, Staphylococcus aureus, grup A betahemolytic Streptococcus (Streptococcus pyogenes), Bacteroides, Fusobacterium, dan Peptostreptococcus spesies. Hasil kultur kadangkadang menunjukkan suatu Neisseria, Pseudomonas, Escherichia dan Haemophilus sp. Proporsi Methicillin-Resistant Staphylococcus Aureus atau MRSA terkait infeksi ruang leher dalam secara signifikan meningkat di beberapa wilayah Amerika 
Serikat. Suatu tinjauan retrospektif menyimpulkan bahwa MRSA lebih cenderung menginfeksi pasien dengan usia yang lebih muda, tapi abses dengan lokasi medial sangat kecil kemungkinannya untuk infeksi MRSA dan methicillin-sensitive Staphylococcus aureus. ${ }^{[8-12]}$

Infeksi leher dalam lebih sering datang dengan keluhan demam, bengkak pada leher, odinofagia, disfagia, sakit tenggorokan, dan penurunan intake oral. Gejala-gejala ini biasanya muncul selama kurang lebih 3-5 hari. Kadang disertai agitasi, batuk, dehidrasi, drooling, mendengkur, stridor, tortikolis, dan leher kaku. Hal penting yang perlu ditanyakan dalam riwayat penyakit termasuk durasi dan perkembangan gejala, infeksi saluran pernapasan atas yang terjadi sebelumnya, tindakan yang melibatkan leher misalnya: tindakan pada gigi, intubasi, terapi antibiotik sebelumnya, faktor risiko MRSA, dan kemungkinan immunocompromise. ${ }^{[13]}$

Computed tomography atau CT scan dengan kontras IV paling sering digunakan untuk membedakan antara limfadenitis dan abses pada infeksi leher dalam. Sering terjadi ketidakmampuan menemukan pus pada saat melakukan tindakan pada yang dipastikan abses dari CT scan,. Roberson dkk. menunjukkan bahwa kontur dinding abses yang bergelombang merupakan indikator yang lebih baik adanya pus. ${ }^{[14]}$

Komplikasi abses leher jarang terjadi tetapi dapat membawa angka kesakitan yang tinggi dan kematian. Hal ini biasanya terkait dengan keterlambatan dalam diagnosis atau pengobatan. Penderita dengan abses atau ancaman terjadinya komplikasi terutama terhadap jalan nafas, abses yang tampak pada ruang fasia kepala leher dan mereka yang keadaannya tidak membaik setelah pemberian antibiotika parenteral 48 jam. Keberhasilan terapi bedah tergantung pada visualisasi yang bagus, kontrol pembuluh darah yang memadai, insisi luas, dan drainase terbuka. ${ }^{\lceil 5,11,15]}$

Obstruksi jalan nafas dan kematian bisa terjadi. Penyebaran infeksi sepanjang danger space cepat dapat menyebabkan mediastinitis. Meskipun komplikasi ini ja- rang, tetap bisa terjadi jika ada keterlambatan dalam penatalaksanaan abses leher. $[3,5,16]$

\section{SIMPULAN}

Telah dilaporkan satu kasus, perempuan, 5 tahun dengan diagnosis abses submandibula dekstra. Diagnosis ditegakkan berdasarkan anamnesis dan hasil pemeriksaan klinis serta pemeriksaan laboratorium penderita.

Penatalaksanaan pada penderita dilakukan dengan tindakan insisi drainase untuk evakuasi pus dari daerah submandibula dekstra serta pemberian terapi antibiotika. Diperlukan juga untuk terapi sumber infeksi yang pada kasus ini berasal dari infeksi gigi.

Keterlambatan diagnosis atau kesalahan diagnosis dapat menimbulkan konsekuensi terjadinya komplikasi berupa mediastinitis bahkan kematian.

\section{DAFTAR PUSTAKA}

1. Hartmann RW. Ludwig Angina in Children. Available at http:// www.aafp.orq. Accessed on 15 march 2011

2. Kinzer S, Pfeiffer J, Becker $\mathrm{S}$ et al. Severe Deep Neck Space Infections and Mediastinitis of Odontogenic Origin: Clinical Relevance and Implications for Diagnosis and Treatment. Acta Oto-Laryngol, 2009;129: p62-70

3. Raju R, Digoy GP. Deep Space Neck Infection. In Mitchell RB, Pereira KD (editor). Otolaryngology for the Clinician. Saint Louis, Springer Science, 2009. p223-9

4. Songu M, Demiray U, Adibell ZH et al. Bilateral Deep Neck Space Infection: a Case Report and Review of the Literature. Acta Otorhinolaryngol Italica 2011; 31: p1 $-4$

5. Gadre AK, Gadre KC. Infections of the Deep Spaces of the Neck. In Bailey BJ, Johnson JT, Newlands SD 
(editors). Head and Neck SurgeryOtolaryngology. Lippincot Williams and Wilkins 2006; $4^{\text {th }}$ ed: p665-82

6. Rizzo PB, Mosto MC. Submandibular Space Infection: a Potentially Lethal Infection. International Journal of Infect Diseases. Elsevier 2009, 13, p327-33

7. Marioni G, Rinaldi R, Staffieri C et al. Deep Neck Infection with Dental Origin: Analysis of 85 consecutive Cases (2000-2006). Acta OtoLaryngol, 2008; 128: p201-6

8. Quinn JB, Ryan MW. Deep Neck Spaces and Infections. Available at: http//www.utmb.edu/otoref/grnds/ deep-neck-infection-051005. Accessed on 15 March 2011.

9. Cengiz AB, Kara A, Kanra $G$ et al. Acute Neck Infections. Turkish Journal. 2004; 46: p153-8

10. David ML. Ludwigs angina : Diagnosis and treatment. Hospital physician 2002; p31-7

11. Eric R, Gilespie MB. Deep neck space infection. In : Paul WF, Valerie JL, editors. Cummings otolaryngology head and neck surgery. $5^{\text {th }}$ edition. Philadelpia: Elsevier, 2010. p.631-52.

12. James M. Odontogenic infection. In : Paul WF, Valerie JL, editors. Cummings otolaryngology head and neck surgery. $5^{\text {th }}$ edition. Philadelpia: Elsevier, 2010. p.561-94.

13. Lawson W, Reino AJ, Westreich RW. Odontogenic Infections. In Bailey BJ, Johnson JT, Newlands SD (editors). Head and Neck SurgeryOtolaryngology. Lippincot Williams and Wilkins 2006; $4^{\text {th }}$ ed: p615-30

14. Golberg MH: Odontogenic Infections and deep fascial space infections of odontogenic origin. In: Topazian RG, Goldberg $\mathrm{MH}$ (editors): Oral and Maxillofacial Infection, ed 3. Philadelphia, WB Saunders, 1993, p206.

15. Rahardjo SP. Penatalaksanaan Angina Ludwig. Dexa Media, Vol. 21, Januari-Maret 2008, p32-5

16. Modul Leher - Abses Leher Dalam. Kolegium Ilmu Kesehatan Telinga Hidung Tenggorok Bedah Kepala Leher 2008; Edisi I 